\title{
Interaction of $\mathrm{S}_{13}-\mathrm{PV}$ cell penetrating peptide with model membranes: relevance to peptide translocation across biological membranes
}

\author{
MIGUEL MANO,,, $\mathrm{b} b$ ANA HENRIQUES, ${ }^{c}$ ARTUR PAIVA, ${ }^{c}$ MANUEL PRIETO, ${ }^{d}$ FRANCISCO GAVILANES, ${ }^{e}$ \\ SÉRGIO SIMÕES ${ }^{a, f}$ and MARIA C. PEDROSO DE LIMA ${ }^{a, b *}$ \\ a Centro de Neurociências e Biologia Celular, Universidade de Coimbra, Portugal \\ b Departamento de Bioquímica, Faculdade de Ciências e Tecnologia, Universidade de Coimbra, Portugal \\ c Centro de Histocompatibilidade de Coimbra, Portugal \\ a Centro de Química-Física Molecular, Instituto Superior Técnico, Lisboa, Portugal \\ e Departamento de Bioquímica y Biologia Molecular I, Universidad Complutense de Madrid, Spain \\ ${ }^{f}$ Faculdade de Farmácia, Universidade de Coimbra, Portugal
}

Received 11 January 2007; Accepted 13 January 2007

\begin{abstract}
Cell penetrating peptides (CPPs) have been successfully used to mediate the intracellular delivery of a wide variety of molecules of pharmacological interest both in vitro and in vivo, although the mechanisms by which the cellular uptake occurs remain unclear and controversial. Following our previous work demonstrating that the cellular uptake of the S4 13 -PV CPP occurs mainly through an endocytosis-independent mechanism, we performed a detailed biophysical characterization of the interaction of this peptide with model membranes. We demonstrate that the interactions of the $\mathrm{S} 4_{13}$-PV peptide with membranes are essentially of electrostatic nature. As a consequence of its interaction with negatively charged model membranes, the $\mathrm{S} 4_{13}-\mathrm{PV}$ peptide becomes buried into the lipid bilayer, which occurs concomitantly with significant peptide conformational changes that are consistent with the formation of a helical structure. Comparative studies using two related peptides demonstrate that the conformational changes and the extent of cell penetration are dependent on the peptide sequence, indicating that the helical structure acquired by the $\mathrm{S} 4_{13}-\mathrm{PV}$ peptide is relevant for its nonendocytic uptake. Overall, our data suggest that the cellular uptake of the $\mathrm{S} 4_{13}-\mathrm{PV} \mathrm{CPP}$ is a consequence of its direct translocation through cell membranes, following conformational changes induced by peptide-membrane interactions. Copyright ( 2007 European Peptide Society and John Wiley \& Sons, Ltd.
\end{abstract}

Keywords: cell penetrating peptide; protein transduction domain; peptide-membrane interaction; tryptophan fluorescence; circular dichroism; amphipathic alpha helix

\section{INTRODUCTION}

Over the last decade, CPPs have attracted a lot of interest from the scientific community, not only due to their capacity to translocate across eukaryotic cell membranes through an elusive temperature-insensitive and energy-independent mechanism, but mostly due to the ability of these peptides to mediate the intracellular delivery of a wide variety of molecules of pharmacological interest, which has motivated their extensive use for delivery purposes both in vitro and in vivo [reviewed in 1-5].

Although the number of peptides described as cell penetrating has increased considerably during the last years (both of natural origin and synthetic peptides, e.g. [6-8]), the high variability of their amino acid sequences

Abbreviations: CPP, cell penetrating peptide; POPC, 1-Palmitoyl-2Oleoyl-sn-Glycero-3-Phosphocholine; POPG, 1-Palmitoyl-2-Oleoyl-snGlycero-3-[Phospho-rac-(1-glycerol)]; CD, circular dichroism; HSPG, heparan sulfate proteoglycan.

\footnotetext{
* Correspondence to: Maria C. Pedroso de Lima, Departamento de Bioquímica, Faculdade de Ciências e Tecnologia, Universidade de Coimbra, Apartado 3126, 3001-401 Coimbra, Portugal;

e-mail: mdelima@ci.uc.pt
}

has hampered the identification of any consensus sequence. Nonetheless, CPPs are usually short, highly basic peptides, and in some cases exhibit the ability to be arranged in amphipathic helical structures. The Tat and Penetratin peptides, which are derived from the HIV-1 Tat protein and from the homeodomain of the Antennapedia protein of Drosophila, respectively [9, 10], as well as the synthetic Pep-1 peptide [11], are among the best-characterized CPPs.

Despite the extensive research on the ability of CPPs to traverse cell membranes and promote the intracellular uptake of various cargo molecules, the mechanisms underlying the cellular uptake of CPPs, as well as that of peptide conjugates remain a matter of extensive debate and controversy. Following several reports demonstrating that the apparent intracellular and nuclear accumulation of several CPPs was related to artifactual observations caused by a redistribution of membrane-bound peptide molecules upon cell fixation [12-14], a growing number of studies have shown the involvement of well-characterized endocytic pathways in the internalization of several peptides and peptide conjugates [15-20]. At present, it is clear that these mechanisms are not mutually exclusive and that 
different peptides rely on distinct mechanisms to enter cells.

Recently, we have demonstrated that the $\mathrm{S} 4_{13}-\mathrm{PV}$ CPP (ALWKTLLKKVLKAPKKKRKVC), a chimeric peptide that results from the combination of a sequence derived from the Dermaseptin S4 peptide with the nuclear localization signal of the simian virus 40 (SV40) large $\mathrm{T}$ antigen [21], accumulates very efficiently inside cells, and particularly inside the nucleus, through a rapid, dose-dependent and nontoxic process, independently of cell fixation $[22,23]$. Comparative analysis of peptide uptake by mutant cells lacking HSPGs showed that the presence of these negatively charged components at cell surface markedly facilitates the cellular uptake of the S4 ${ }_{13}$-PV peptide. Most importantly, by applying several experimental approaches, we have demonstrated that the main mechanism responsible for the cellular uptake of the $\mathrm{S} 4_{13}-\mathrm{PV}$ peptide is distinct from endocytosis, most likely involving direct penetration of the peptide across cell membranes following changes in peptide conformation induced by the lipid environment [22,23].

Aiming at understanding the sequence of events that are on the basis of this translocation process, we performed a detailed biophysical characterization of the interaction of the $\mathrm{S} 4_{13}$-PV CPP with model membranes of different phospholipid composition and charge density. The results presented here demonstrate that the initial interaction of the $\mathrm{S} 4_{13}-\mathrm{PV}$ CPP with the target membranes is of electrostatic nature, and hence highly dependent on the content of negatively charged components on the target membrane. As a consequence of this peptide-membrane interactions, significant changes of both the intrinsic fluorescence and dynamics of the $\mathrm{S} 4_{13}$-PV peptide are observed. Concomitantly, an increase in the helical content of the $\mathrm{S} 4_{13}-\mathrm{PV}$ peptide was observed, indicating that upon interaction with the target membranes, the peptide undergoes significant conformational changes. Comparative analysis using two related peptides demonstrates that the conformational changes are dependent on the peptide sequence, suggesting that the alpha-helical structure acquired by the $\mathrm{S} 4_{13}$-PV peptide is intricately related to its capacity to translocate across cell membranes.

\section{MATERIALS AND METHODS}

\section{Peptides}

High purity (>95\%) $\mathrm{S} 4_{13}-\mathrm{PV}$ peptide (ALWKTLLKKVLKAPKKKRKVC), reverse NLS peptide (ALWKTLLKKVLKAVKRKKKPC) and scrambled peptide (KTLKVAKWLKKAKPLRKLVKC) were obtained from Thermo Electron (Thermo Electron GmbH, Germany). During synthesis, peptides were either fluorescently labeled with 5-(6)-tetramethylrhodamine (TAMRA), or modified with an acetyl group at the $N$-terminus, and further modified by introducing an amide group at the $C$-terminus. Freeze-dried peptides were reconstituted in high purity water.
Peptide concentration was determined by amino acid analysis and light absorption at $280 \mathrm{~nm}$. Amino acid analysis was performed in a Beckman 6300 automatic analyzer, following acid hydrolysis of the peptides.

\section{Liposome Preparation}

Large unilamellar vesicles were prepared by extrusion of multilamellar vesicles composed of POPC (Avanti Polar Lipids, Alabaster, USA), POPG (Avanti), or mixtures of these two lipids at different molar ratios [(POPC: POPG $(50: 50)$ and POPC : POPG $(80: 20)]$.

Lipid solutions in chloroform were mixed at the desired molar ratios, and dried under vacuum, at room temperature, using a rotary evaporator. The dried lipid films were then hydrated with $1.0 \mathrm{ml}$ high purity water, and the multilamellar vesicles obtained were briefly sonicated and extruded 21 times through two-stacked polycarbonate filters (100 nm pore diameter) using a Liposofast device (Avestin, Toronto, Canada).

Total lipid concentrations of the resulting lipid vesicles were determined by the Bartlett method [24], and $10 \mathrm{~mm}$ stock solutions of the different liposome formulations were prepared.

\section{Steady-state Fluorescence Spectroscopy}

Steady-state fluorescence measurements were performed in a SPEX Fluorolog 2 spectrofluorometer, at room temperature, using $10 \times 2$ or $5 \times 5 \mathrm{~mm}$ quartz cuvettes.

Interaction of $\mathrm{S} 4_{13}-\mathrm{PV}$ peptide with lipid vesicles was assessed by following peptide intrinsic fluorescence upon sequential addition of small volumes of concentrated vesicle stock solutions to peptide samples, up to a lipid/peptide molar ratio of 40 . Experiments were performed in $10 \mathrm{~mm}$ sodium phosphate buffer ( $\mathrm{pH}$ 7.0). The concentration of $\mathrm{S}_{13}{ }_{13}^{-}$ PV peptide, as well as that of monomeric L-tryptophan, which was used as control, was $2.5 \mu \mathrm{M}$. Excitation wavelength was $280 \mathrm{~nm}$ and fluorescence emission was scanned from 300 to $400 \mathrm{~nm}$.

All spectra were corrected for background contributions of buffer, and of different concentrations of vesicles. Spectra were not corrected for the photomultiplier wavelength dependence.

\section{Tryptophan Fluorescence Quenching Experiments}

Quenching of tryptophan fluorescence by acrylamide was evaluated in aqueous buffer, in the presence or absence of lipid vesicles, at different lipid/peptide molar ratios.

The Stern-Volmer quenching constants $\left(K_{S V}\right)$ for the $\mathrm{S}_{13}{ }^{-}$ PV peptide and monomeric L-tryptophan were determined by linear regression using the Stern-Volmer equation [25,26]:

$$
\frac{F_{0}}{F}=1+K_{S V}[Q]
$$

where $F_{0}$ and $F$ are the fluorescence intensities of tryptophan emission in the absence and presence of the quencher, respectively, and $[Q]$ is the molar concentration of the quencher in the sample.

Emission spectra of the $\mathrm{S} 4_{13}-\mathrm{PV}$ peptide $(2.5 \mu \mathrm{M})$ and of monomeric L-tryptophan $(2.5 \mu \mathrm{M})$ were acquired as described previously, in the presence of different acrylamide concentrations (5-100 mm). Acrylamide was added from a $1.0 \mathrm{~m}$ 
aqueous stock solution. Spectra were corrected for background fluorescence of buffer, vesicles and different concentrations of acrylamide. Spectra were additionally corrected for the inner filter effect, as described elsewhere [27], considering $\varepsilon_{280 \mathrm{~nm}}($ acrylamide $)=3 \mathrm{~m}^{-1} \mathrm{~cm}^{-1}$ and $\varepsilon_{280 \mathrm{~nm}}(\operatorname{trp})=$ $5690 \mathrm{~m}^{-1} \mathrm{~cm}^{-1}$.

\section{Time-resolved Fluorescence Spectroscopy}

Time-resolved fluorescence measurements of $\mathrm{S} 4_{13}$-PV peptide $(5 \mu \mathrm{M})$ in the presence of POPG vesicles, at a lipid/peptide molar ratio of 10, were performed in $10 \mathrm{~mm}$ sodium phosphate buffer, pH 7.0. The time-resolved instrumentation (correlated single-photon timing technique) was described previously [28]. Excitation wavelength was $287 \mathrm{~nm}$ and emission was detected at the magic angle $\left(54.7^{\circ}\right)$ relative to the vertically polarized beam. The number of counts on the peak channel was 20000 and the number of channels per curve used for analysis was 800. Data analysis was carried out using a nonlinear, leastsquare iterative convolution method based on the algorithm of Marquardt [29]. The goodness of the fit was judged from the reduced $\chi^{2}$, weighted residuals and autocorrelation plots.

More than one component was required to describe the decay of tryptophan fluorescence in the peptide,

$$
I(t)=\sum \alpha_{i} \exp \left(-t / \tau_{i}\right)
$$

and in this case, the average lifetime $\bar{\tau}$ of a fluorophore is defined as (e.g. [25]),

$$
\bar{\tau}=\sum_{i} a_{i} \tau_{i}^{2} / \sum a_{i} \tau_{i}
$$

where $a_{i}$ are the normalized preexponentials (amplitudes) and $\tau_{i}$ the lifetime components.

The time-resolved fluorescence anisotropies were determined using Glan-Thompson polarizers, and calculated according to:

$$
r(t)=\frac{I_{\mathrm{VV}}(t)-G I_{\mathrm{VH}}(t)}{I_{\mathrm{VV}}(t)+2 G I_{\mathrm{VH}}(t)}
$$

where the different intensities are the vertical $\left(I_{\mathrm{VV}}\right)$ and horizontal $\left(\mathrm{I}_{\mathrm{VH}}\right)$ components of the fluorescence emission with excitation vertical to the emission axis. The intensity decays of polarized light $I_{\mathrm{VV}}(t)$ and $I_{\mathrm{VH}}(t)$ were obtained with the same accumulation time. The instrumental factor $G$ for the timeresolved instrumentation is 1 , once a scrambler is used before the detector.

\section{Circular Dichroism Spectroscopy}

CD spectra were acquired in a Jasco J-715 spectropolarimeter using $1.0 \mathrm{~mm}$ quartz cuvettes. Experiments were performed at $15^{\circ} \mathrm{C}$, in $10 \mathrm{~mm}$ sodium phosphate buffer (pH 7.0), or $20 \%$ trifluoroethanol (TFE) in the same buffer. Five spectra were collected and averaged for each sample. Peptide concentrations ranged from 5 to $50 \mu \mathrm{M}$, and maximal lipid concentration was $0.2 \mathrm{~mm}$. All spectra were corrected for background contributions of buffers and lipid vesicles, and smoothed using the Jasco J-715 noise reduction software.

To facilitate interpretation of $\mathrm{CD}$ spectra, the relative contribution of three secondary structure elements ( $\alpha$-helix, $\beta$-structure and random coil) to the overall structure of the peptide was estimated by computer fitting of the spectra according to the algorithm convex constraint analysis (CCA).

\section{Cells}

HeLa cells (human epithelial cervical carcinoma) were maintained at $37^{\circ} \mathrm{C}$, under $5 \% \mathrm{CO}_{2}$, in Dulbecco's modified Eagle's medium (DMEM)/high glucose (DMEM; Sigma, St. Louis, MO) supplemented with $10 \%(\mathrm{v} / \mathrm{v})$ heat-inactivated fetal bovine serum (Biochrom KG, Berlin, Germany), and with 100 units penicillin and $100 \mu \mathrm{g} / \mathrm{ml}$ streptomycin.

\section{Peptide Cellular Uptake Studies}

For experiments on peptide uptake, $0.8 \times 10^{5} \mathrm{HeLa}$ cells/well were seeded onto 12 -well plates (flow cytometry) or a 12 -well plate containing 16-mm glass coverslips (confocal microscopy), 24 hours prior to incubation with the peptide. The cells were then washed with phosphate-buffered saline (PBS) and incubated with $1.0 \mu \mathrm{M}$ of $\mathrm{S} 4_{13}-\mathrm{PV}$ peptide, reverse NLS peptide or scrambled peptide, in serum-free DMEM, for 30 minutes at $37^{\circ} \mathrm{C}$. Analysis of peptide internalization was performed by confocal laser-scanning microscopy and flow cytometry.

For analysis of the subcellular localization of the peptides by confocal microscopy, following peptide-cell incubation, the cells were washed and mounted in PBS, and immediately visualized. All observations were performed using live cells, in a Zeiss LSM510 laser-scanning microscope.

Flow cytometry analysis was performed in live cells, using a Becton Dickinson FACSCalibur flow cytometer. Data were obtained and analyzed using Cellguest software (BD Biosciences). After incubation with the different peptides, cells were washed once with PBS and trypsinized (10 minutes at $37^{\circ} \mathrm{C}$ ) to remove extracellular, surface-bound peptide. The cells were then further washed, resuspended in PBS, and immediately analyzed. Live cells were gated by forward/side scattering from a total of 10000 events.

\section{RESULTS}

\section{Extent of Interaction of $\mathrm{S}_{13}-\mathrm{PV}$ Peptide with Target Membranes is Dependent on Membrane Charge Density}

To characterize the interaction of the $\mathrm{S} 4_{13}-\mathrm{PV}$ peptide with membranes, changes in the intrinsic fluorescence of the peptide, which results from a single tryptophan residue located at the $N$-terminus (aa 3), were analyzed in the presence of lipid vesicles of different charge densities (neutral POPC vesicles and negatively charged POPC: POPG $(80: 20)$, POPC:POPG $(50: 50)$ or POPG vesicles).

In aqueous buffer, the wavelength of maximal fluorescence emission observed for the $\mathrm{S} 4_{13}-\mathrm{PV}$ peptide $\left(\lambda_{\mathrm{em}}\right)$ was $354 \mathrm{~nm}$ (Figure 1(A)), a result similar to that of monomeric L-tryptophan under the same experimental conditions (data not shown).

Upon interaction with the negatively charged vesicles, a clear change of maximal fluorescence emission of the 
$\mathrm{S} 4_{13}$-PV peptide toward shorter wavelengths (blue shift) was observed, as a function of the lipid/peptide molar ratio $\left(\lambda_{\mathrm{em}}=324 \mathrm{~nm}\right.$ in the presence of POPG vesicles, $\mathrm{L} / \mathrm{P} \geq 8$ ), concomitantly with a significant increase of fluorescence intensity (Figure 1(A)).

On the basis of the increase in the fluorescence quantum yield of tryptophan observed upon interaction with the negatively charged membranes (Figure 1(B)), the extent of interaction, as assessed from the lipid/water partition coefficient which can be described by,

$$
K_{\mathrm{p}}=\frac{n_{\mathrm{L}} / V_{\mathrm{L}}}{n_{\mathrm{W}} / V_{\mathrm{W}}}
$$

where $n_{i}$ stands for mols of peptide in phase $i$ and $V_{i}$ for volume of the phase, can be determined. The phase is either aqueous $(i=\mathrm{W})$ or lipidic $(i=\mathrm{L})$. The relationships and assumptions used to determine the partition coefficient $\left(K_{\mathrm{p}}\right)$ were previously described [30],

$$
I=\frac{I_{\mathrm{W}}+I_{\mathrm{L}} K_{\mathrm{p}} \bar{V}_{\mathrm{L}}[L]}{1+K_{\mathrm{p}} \bar{V}_{\mathrm{L}}[L]}
$$

where $I$ is the fluorescence intensity for each lipid concentration $[L]$, and $I_{i}$, the values in phase $i(i=\mathrm{W}$, L). The lipid molar volume $\bar{V}_{\mathrm{L}}=0.637 \mathrm{dm}^{3} \mathrm{M}^{-1}$ used in this work is obtained from extrapolation of available data in the literature [31].

A nonlinear fit of Eqn (6) to the data (Figure 1(B)) yields the values of $I_{L}$ and $K_{\mathrm{p}}$. The partition coefficients calculated for the $\mathrm{S} 4_{13}$-PV peptide in the presence of vesicles composed of POPC:POPG $(80: 20)$, POPC : POPG (50:50) and POPG were $0.23 \times 10^{5}, 1.17 \times$ $10^{5}$ and $1.96 \times 10^{5}$, respectively, clearly indicating that
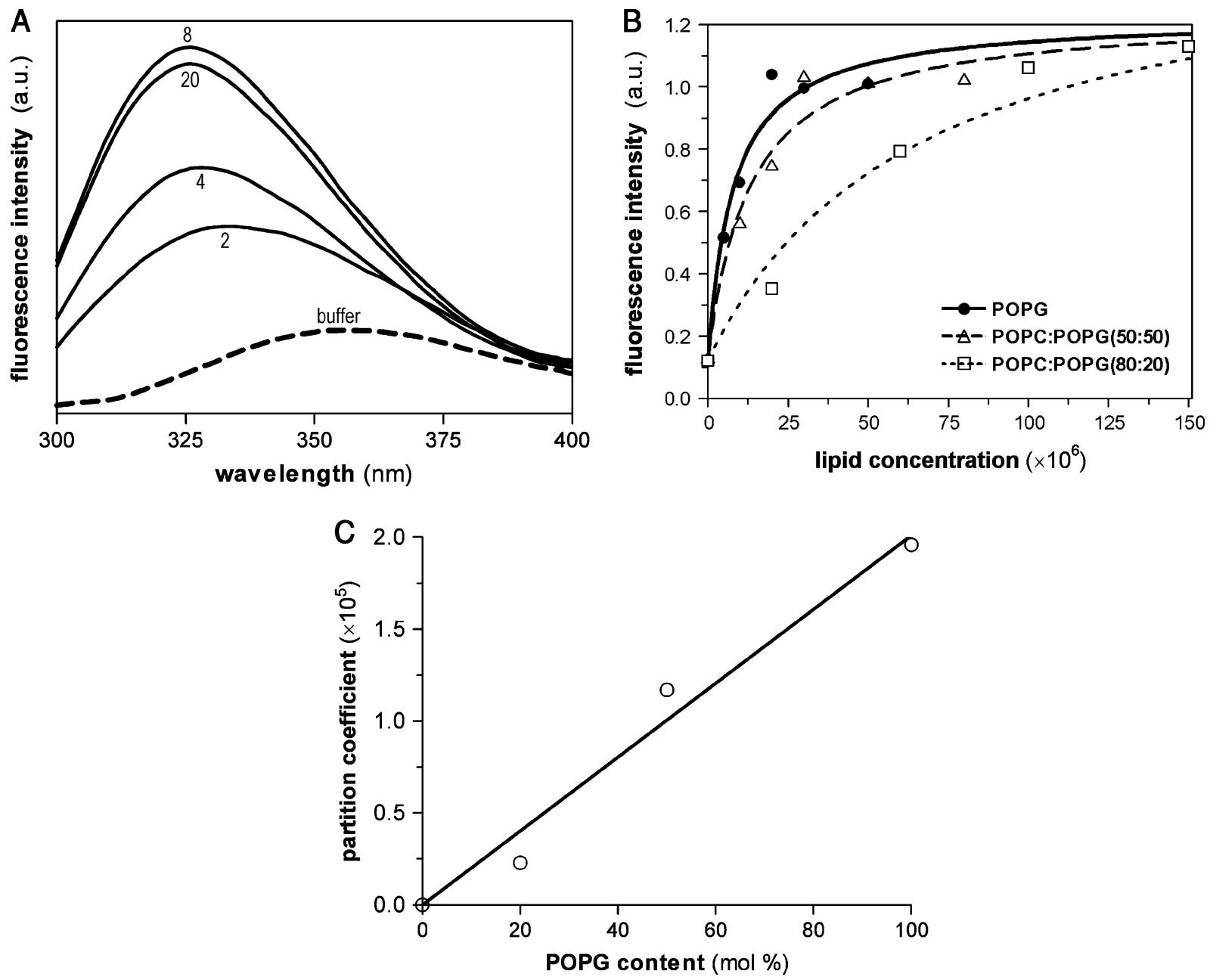

Figure 1 (A) Effect of target membranes on the intrinsic fluorescence of the $\mathrm{S} 4_{13}$-PV peptide. Spectra were acquired in sodium phosphate buffer, pH 7.0 (dashed line; buffer), or in the presence of negatively charged vesicles composed of POPG (solid lines; lipid/peptide molar ratios are indicated in the figure). Excitation wavelength was $280 \mathrm{~nm}$ and fluorescence emission was scanned from 300 to $400 \mathrm{~nm}$. (B) Partition of S4 13 -PV peptide into lipid vesicles of different composition. Changes of peptide fluorescence intensity induced by the different lipid vesicles were used to calculate the partition coefficients $\left(K_{\mathrm{p}}\right)$, by a nonlinear regression fitting using Eqn (6). Excitation wavelength was $280 \mathrm{~nm}$ and fluorescence emission was scanned from 300 to $400 \mathrm{~nm}$. Partition coefficients calculated in the presence of different vesicles (except POPC) are displayed in panel (C). (C) Effect of membrane charge density on the partition coefficient of the $\mathrm{S} 4_{13}-\mathrm{PV}$ peptide. 
the extent of peptide-membrane interactions is dependent on the density of negatively charged components in the target membranes (Figure 1(C)).

At low lipid/peptide molar ratios, the magnitude of the blue shift of maximal fluorescence emission of the $\mathrm{S} 4_{13}-\mathrm{PV}$ peptide induced by the negatively charged vesicles, increased with the charge density of the membranes (POPC:POPG $(80: 20)<$ POPC:POPG (50:50) < POPG), as well as with lipid/peptide ratio (Figure 2; Table 1). As expected, at higher lipid/peptide ratios, the difference between the magnitudes of the blue shifts induced by the different negatively charged vesicles was progressively less pronounced, the shifts being comparable at lipid/peptide molar ratios of 40 , or higher (Figure 2; Table 1).

No changes in the fluorescence emission spectra of the $\mathrm{S} 4_{13}$-PV peptide were observed in the presence of neutral lipid vesicles composed of POPC, even at high lipid/peptide molar ratios (Figure 2; Table 1).

Overall, the observed spectral changes clearly indicate that the interaction of the $\mathrm{S} 4_{13}$-PV peptide with membranes is essentially of electrostatic nature. Moreover, the shift of peptide maximal fluorescence toward shorter wavelengths observed in the presence of negatively charged vesicles indicates that, following its interaction with these vesicles, the $\mathrm{S} 4_{13}-\mathrm{PV}$ peptide becomes localized in a highly hydrophobic environment.

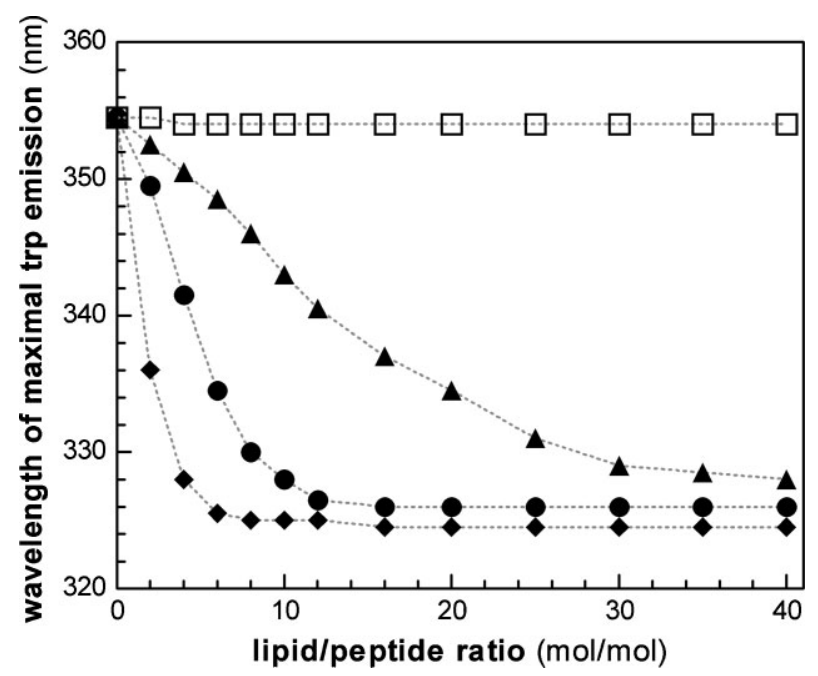

Figure 2 Effect of target membrane composition and lipid/peptide molar ratio on the wavelength of maximal fluorescence emission of the $\mathrm{S} 4_{13}-\mathrm{PV}$ peptide. Spectra of $\mathrm{S} 4_{13}$-PV peptide were obtained in the presence of lipid vesicles composed of POPC ( $\square$ ), POPC : POPG $(80: 20)(\boldsymbol{\Delta})$, POPC : POPG $(50: 50)(\bullet)$ or POPG $(\diamond)$, at different lipid/peptide molar ratios. Spectra were acquired in sodium phosphate buffer, $\mathrm{pH} 7.0$; excitation wavelength was $280 \mathrm{~nm}$ and fluorescence emission was scanned from 300 to $400 \mathrm{~nm}$.
Table 1 Effect of the target membrane on the intrinsic fluorescence of $\mathrm{S} 4_{13}-\mathrm{PV}$ peptide and its quenching by acrylamide, as a function of lipid/peptide ratio. Results obtained for monomeric L-tryptophan, which was used as control, are shown for comparison. Stern-Volmer quenching constants $\left(K_{S V}\right)$ were calculated by fitting Eqn (1) to the experimental data, as described in Materials and Methods

$$
\mathrm{L} / \mathrm{P}^{\mathrm{a}} \quad \lambda_{\mathrm{em}}(\mathrm{nm})^{\mathrm{b}} \quad \mathrm{K}_{\mathrm{SV}}\left(\mathrm{M}^{-1}\right)
$$

$\begin{array}{lccr}\text { L-tryptophan } & & \\ \text { buffer, pH 7.0 } & - & 356 & 18.5 \\ \text { POPG } & 40 & 356 & 19.6 \\ \text { S4 } 13 \text {-PV peptide } & - & - & \\ \text { buffer, pH 7.0 } & - & 354 & 15.7 \\ \text { POPC } & 40 & 354 & 14.8 \\ \text { POPC : POPG }(80: 20) & 10 & 343 & 8.7 \\ \text { POPC : POPG }(80: 20) & 20 & 334 & 5.7 \\ \text { POPC : POPG }(80: 20) & 40 & 328 & 2.3 \\ \text { POPC : POPG }(50: 50) & 40 & 326 & 2.1 \\ \text { POPG } & 40 & 324 & 3.1 \\ & \\ \text { a Molar ratio of lipid to monomeric L-tryptophan or S4 } \\ \text { peptide. } \\ \text { b Wavelength of maximal fluorescence emission. } \\ \text { S4 } 13 \text {-PV Peptide Becomes Buried into the Lipid } \\ \text { Bilayer as a Consequence of its Interaction with } \\ \text { Negatively Charged Membranes }\end{array}$

To evaluate the degree of exposure of the peptide to the aqueous environment following its interaction with membranes, the extent of quenching of tryptophan fluorescence by the neutral hydrophilic quencher acrylamide was determined.

Quenching efficiency of the intrinsic fluorescence of the $\mathrm{S} 4_{13}$-PV peptide by acrylamide in the presence of POPC phospholipid vesicles was comparable to that in buffer (Figure 3(A), Table 1), demonstrating that the $\mathrm{S} 4_{13}$-PV peptide remains completely exposed to the aqueous environment. Conversely, following interaction of the peptide with negatively charged vesicles, a significant decrease in the efficiency of quenching by acrylamide was observed; at a lipid/peptide molar ratio of 40 , a ratio at which maximal blue shifts were observed, quenching was minimal (Figure 3(A), Table 1). As illustrated by the results obtained with the vesicles composed of POPC: POPG $(80: 20)$, quenching efficiency decreased with increasing lipid/peptide molar ratios (Figure $3(\mathrm{~B})$, Table 1), as expected by the increase in the fraction of peptide incorporated into the membrane.

Quenching of monomeric L-tryptophan, which was used as control, was similar in buffer and in the presence of negatively charged POPG vesicles (Figure 3(A); Table 1).

It should be stressed that the $K_{S V}$ in Table 1, are the product of the bimolecular quenching rate constant by the fluorescence lifetime. Since the 

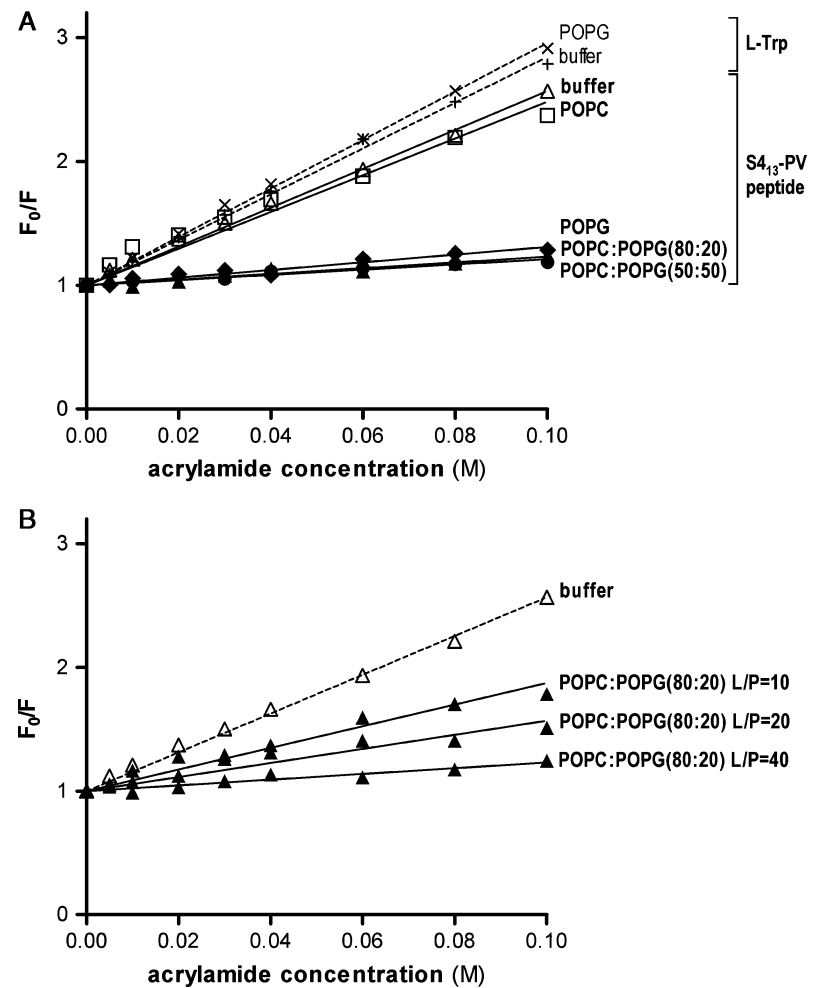

Figure 3 Stern-Volmer plots of acrylamide quenching of the intrinsic fluorescence of monomeric L-tryptophan and S4 13 -PV peptide. (A) Effect of target membrane composition. Quenching of $\mathrm{S} 4_{13}$-PV peptide fluorescence was evaluated in buffer, as well as in the presence of neutral lipid vesicles composed of POPC, or negatively charged vesicles composed of POPC : POPG $(80: 20)$, POPC:POPG $(50: 50)$ or POPG, at a lipid/peptide ratio of 40 . Results of quenching of monomeric L-tryptophan (L-Trp) in buffer and in the presence of POPG vesicles, at a lipid/peptide ratio of 40, are shown for comparison. (B) Effect of lipid/peptide molar ratio. Quenching of intrinsic fluorescence of $\mathrm{S}_{13}-\mathrm{PV}$ peptide was evaluated in the presence of POPC: POPG $(80: 20)$ lipid vesicles, at the indicated lipid/peptide molar ratios. Fluorescence quenching was assessed, following addition of different amounts of acrylamide from a $1.0 \mathrm{~m}$ stock solution. Spectra were acquired in sodium phosphate buffer, $\mathrm{pH}$ 7.0; excitation wavelength was $280 \mathrm{~nm}$ and fluorescence emission was scanned from 300 to $400 \mathrm{~nm}$. Stern-Volmer quenching constants $\left(K_{S V}\right)$ were calculated by fitting Eqn (1) to the experimental data, as described in Materials and Methods (results are summarized in Table 1).

quantum yields and lifetimes increase upon interaction of the peptide with the membranes, higher $K_{S V}$ values would be expected. From the significant decrease observed, it can be concluded that the ruling factor is, in fact, the shielding of the tryptophan to the aqueous environment, and thereby to the acrylamide quencher. Therefore, these results are in agreement with those described above regarding the changes in the fluorescence emission spectra of the $\mathrm{S} 4_{13}-\mathrm{PV}$ peptide, which collectively demonstrate that the $\mathrm{S}_{13^{-}}$ PV peptide, or at least the region of the peptide that contains the tryptophan residue, becomes less exposed to the aqueous environment following its interaction with negatively charged membranes, most likely being inserted into the lipid bilayer.

\section{Dynamics of $\mathrm{S4}_{13}-\mathrm{PV}$ Peptide is Reduced upon Interaction with Negatively Charged Membranes}

The starting point of the analysis of time-resolved anisotropy, from which dynamic information can be obtained, involves the measurement of the fluorescence decay obtained under the magic angle conditions.

The fluorescence decay of the $\mathrm{S} 4_{13}-\mathrm{PV}$ peptide in the presence of POPG vesicles was described by two components, the lifetimes and amplitudes Eqn (2) being $\tau_{1}=1.41 \mathrm{~ns}\left(\alpha_{1}=0.537\right)$ and $\tau_{2}=3.23 \mathrm{~ns}$. The existence of two or even three components for the fluorescence decay of tryptophan is very common and, among other factors, usually attributed to the existence of several rotational conformers of the indole ring [32]. The mean fluorescence lifetime, as determined from Eqn (3), $\bar{\tau}=2.62 \mathrm{~ns}$, is a value common for a peptide interacting with a membrane model system. These data, as well as those for the anisotropy described below, are not biased by any contribution of peptide in water, since the experiments were carried out at a lipid concentration of $50 \mu \mathrm{M}$, and considering the very high value for $K_{\mathrm{p}}$, the molar fraction of peptide in water (which in addition has a smaller quantum yield), is $x_{\mathrm{W}}=0.0045$.

For the time-resolved anisotropy data, at least two rotational correlation times $\left(\theta_{\mathrm{i}}\right)$, and a constant $\left(r_{\infty}\right)$, were needed to describe the experimental decay Eqn (7),

$$
r(t)=\left(r_{\mathrm{o}}-r_{\infty}\right) \times\left[\beta_{1} \exp \left(-t / \theta_{1}\right)+\beta_{2} \exp \left(-t / \theta_{2}\right)\right]+r_{\infty}
$$

where $r_{\mathrm{o}}$ is the fundamental anisotropy, and $\beta_{\mathrm{i}}$ is the amplitude associated to each decay component. Although analysis of the data in which each component of the magic angle fluorescence intensity decay is associated to one rotational correlation time was also performed, no statistically meaningful parameters were recovered from such type of analysis, and therefore a nonassociative model was used.

The experimental decay is shown in Figure 4, and from the fitting of Eqn (7) to the data, the following parameters were recovered: $r_{\mathrm{o}}=0.2, r_{\infty}=0.12, \theta_{1}=$ $0.252 \mathrm{~ns}\left(\beta_{1}=0.414\right)$ and $\theta_{2}=6.93 \mathrm{~ns}$. The obtained fundamental anisotropy or anisotropy at zero time, $r_{\mathrm{o}}$, is the same as that reported by Valeur and Weber in rigid media [33]. This means that there are no additional ultrafast dynamics below the time resolution of the instrumentation (subpicosecond), which is compatible with a peptide strongly immobilized at the membrane; the existence of a limiting anisotropy $r_{\infty}$, which is an evidence of a restricted motion of the tryptophan fluorophore on the timescale of the fluorescence decay, 


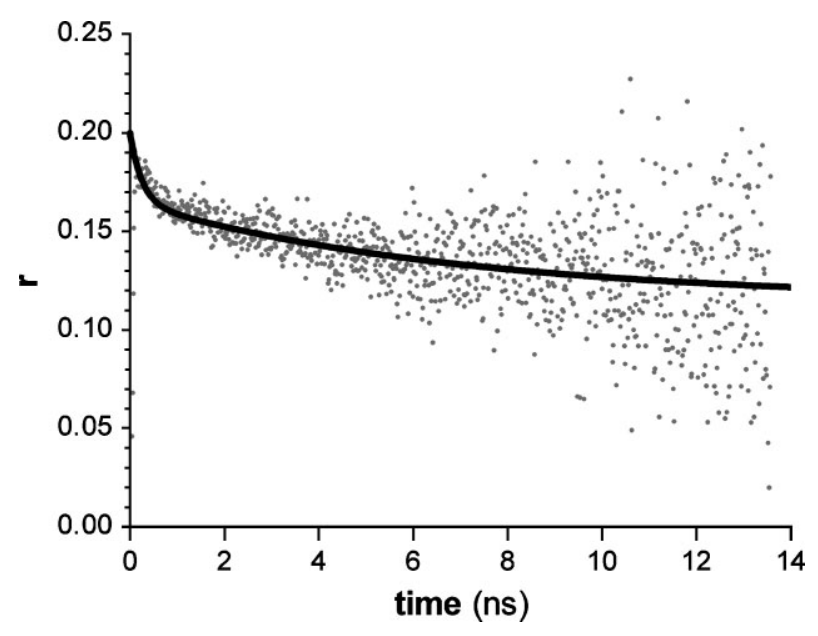

Figure 4 Anisotropy decay of $\mathrm{S} 4_{13}-\mathrm{PV}$ peptide in the presence of POPG vesicles. Decay of $\mathrm{S} 4_{13}$-PV peptide $(5 \mu \mathrm{M})$

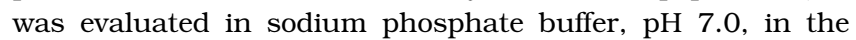
presence of negatively charged vesicles composed of POPG, at a lipid/peptide molar ratio of 10. Anisotropy parameters were obtained by fitting Eqn (7) to the experimental data.

is a further evidence for this situation. Interestingly, the value of 0.12 obtained for $r_{\infty}$ is higher than the ones found for transmembrane peptides [34], but similar to those found for basic peptides in electrostatic interaction with negatively charged membranes [35].

Since the longer rotational correlation time $\theta_{2}$, is more than one order of magnitude higher than the shorter one, $\theta_{1}$, the total anisotropy can be interpreted as the product of two independent depolarizing processes: a first one owing to faster movements of the peptide segment containing the tryptophan residue (with an associated correlation time $\varphi_{\text {segmental }}$, and a second one related to the global rotational motion of the whole peptide (described by $\varphi_{\text {global }}$ [36],

$$
\begin{aligned}
\theta_{2} & =\varphi_{\text {global }} \\
\theta_{1} & =\frac{\varphi_{\text {segmental }} \varphi_{\text {global }}}{\varphi_{\text {segmental }}+\varphi_{\text {global }}}
\end{aligned}
$$

In this way, the time-dependent anisotropy decay can be described by Eqn (10),

$$
\begin{aligned}
r(t)= & r(0)\left[\left(1-S_{1}{ }^{2}\right) \exp \left(-t / \varphi_{\text {segmental }}\right)+\left(1-{S_{2}}^{2}\right){S_{1}}^{2}\right. \\
& \left.\times \exp \left(-t / \varphi_{\text {global }}\right)+{S_{1}}^{2}{S_{2}}^{2}\right]
\end{aligned}
$$

where $S_{1}$ and $S_{2}$ are the order parameters associated, respectively, to the segmental and global peptide dynamics. Values of $S_{1}=0.92$ and $S_{2}=0.83$ were obtained. In the framework of the wobbling in cone model' [37], the maximum cone angles $\alpha$, are given by $\cos \alpha_{\mathrm{i}}=1 / 2\left[\left(8 S_{\mathrm{i}}+1\right)^{1 / 2}-1\right]$, and for this peptide, values of $\alpha_{1}=21^{\circ}$ and $\alpha_{2}=28^{\circ}$ were obtained. Both these values are very small, and specifically the first one, which is associated to the local movements of the tryptophan residue, points out that this part of the peptide is very rigid. In this context, the presence of a lysine near the tryptophan should be stressed, which probably anchors this extreme of the peptide to the negatively charged lipids.

Altogether, these results provide evidence that the dynamics of the $\mathrm{S} 4_{13}-\mathrm{PV}$ peptide is significantly reduced owing to its strong interaction with negatively charged membranes.

\section{S4 ${ }_{13}$-PV Peptide Undergoes Significant Conformational Changes upon Interaction with Negatively Charged Target Membranes}

$\mathrm{CD}$ experiments were performed to determine if the interaction of the $\mathrm{S} 4_{13} \mathrm{PV}$ peptide with membranes induces changes of peptide conformation. Analysis of $\mathrm{CD}$ spectra of the $\mathrm{S} 4_{13}$-PV peptide in buffer demonstrated that the peptide is completely unstructured in aqueous solution (Figure 5(A)). In the presence of vesicles composed of POPC, the CD spectra of the $\mathrm{S} 4_{13^{-}}$ PV peptide were indistinguishable from that obtained in buffer, independently of the lipid/peptide molar ratio, demonstrating that no conformational changes are induced by neutral membranes (Figure 5(A)). In contrast, clear changes in the CD spectra of the $\mathrm{S} 4_{13^{-}}$ PV peptide were observed in the presence of vesicles containing negatively charged phospholipids, demonstrating that interaction of the peptide with these vesicles results in prominent changes in its secondary structure (Figure 5(B), (C), Table 2).

At the lowest lipid/peptide molar ratio examined $(\mathrm{L} / \mathrm{P}=4)$, the extent of peptide conformational changes was highly dependent on the membrane charge density (Figure 5(B), Table 2). At this lipid/peptide ratio, the interaction of the $\mathrm{S} 4_{13}-\mathrm{PV}$ peptide with the POPG vesicles resulted in significant changes of peptide conformation, whereas considerably smaller

Table 2 Effect of target membrane composition and lipid/peptide ratio on the secondary structure of the $\mathrm{S} 4_{13}-\mathrm{PV}$ peptide. Fitting of CD spectra was performed according to the CCA algorithm (refer to Materials and Methods)

L/Pa Random $\alpha$-helix $\beta$-structure

\begin{tabular}{lrlll}
\hline Buffer, pH 7.0 & - & 0.98 & 0.00 & 0.02 \\
POPC & 4 & 1.00 & 0.00 & 0.00 \\
& 8 & 0.98 & 0.00 & 0.02 \\
POPC : POPG $(80: 20)$ & 42 & 1.00 & 0.00 & 0.00 \\
& 8 & 1.00 & 0.00 & 0.00 \\
& 16 & 0.98 & 0.00 & 0.02 \\
POPC : POPG $(50: 50)$ & 32 & 0.70 & 0.05 & 0.13 \\
& 4 & 0.81 & 0.18 & 0.02 \\
POPG & 8 & 0.42 & 0.22 & 0.36 \\
& 4 & 0.29 & 0.29 & 0.42 \\
\hline
\end{tabular}

a Molar ratio of lipid to $\mathrm{S} 4_{13}-\mathrm{PV}$ peptide. 

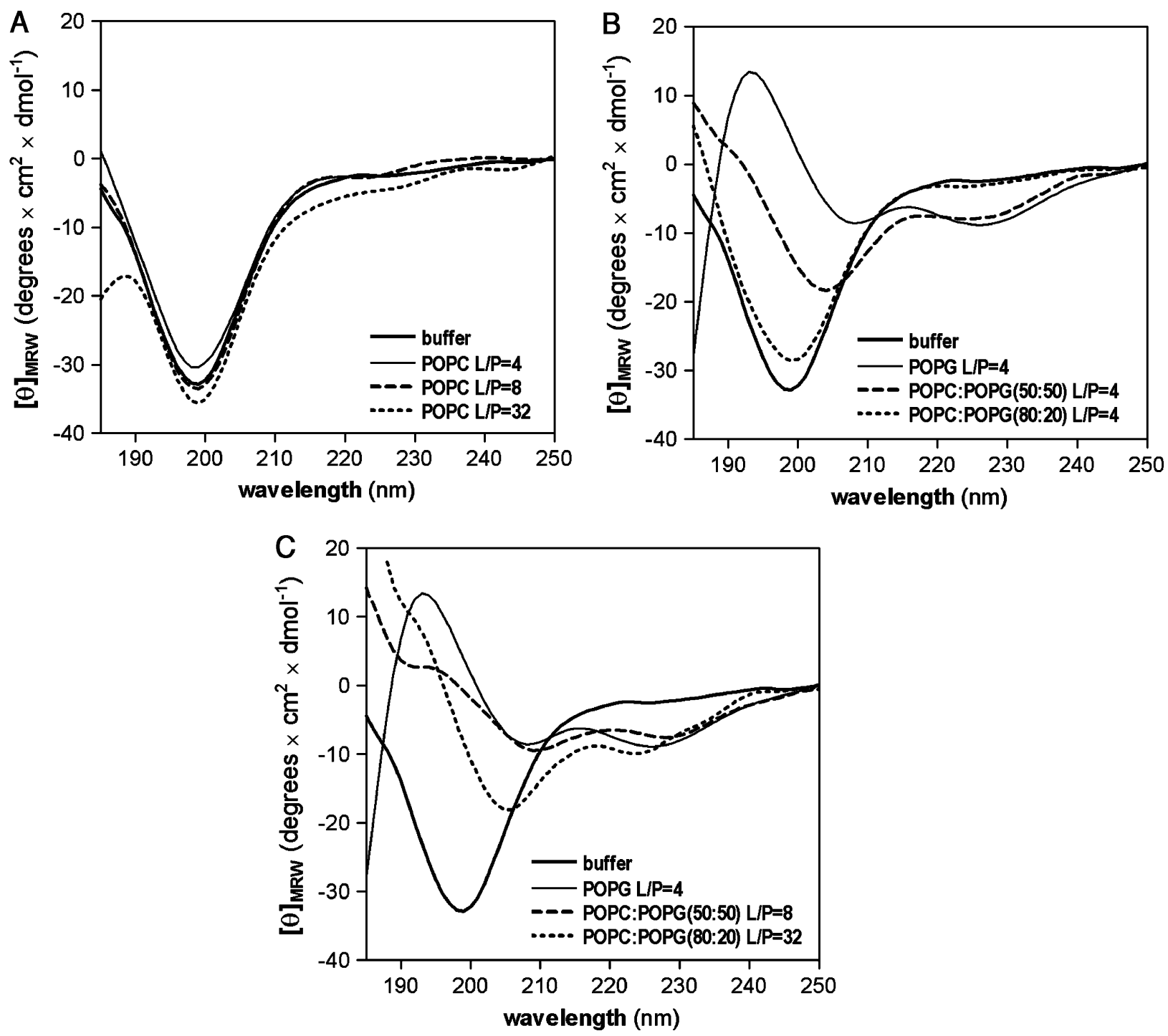

Figure 5 Circular dichroism analysis of $\mathrm{S} 4_{13}-\mathrm{PV}$ peptide conformational changes induced in the presence of (A) neutral vesicles, or $(\mathrm{B}, \mathrm{C})$ negatively charged vesicles. $\mathrm{CD}$ spectra of $\mathrm{S} 4_{13}-\mathrm{PV}$ peptide were acquired in sodium phosphate buffer, $\mathrm{pH} 7.0$, in the presence of neutral target membranes composed of POPC, or negatively charged vesicles composed of POPC:POPG (80:20), POPC : POPG (50:50) or POPG, at the indicated lipid/peptide molar ratios, as described in Materials and Methods. Spectra in panel (C) correspond to the maximal lipid/peptide ratios tested for each of the negatively charged vesicle formulations tested. The relative contribution of three secondary structure elements ( $\alpha$-helix, $\beta$-structure and random coil) to the overall structure of the peptide was estimated by computer fitting (results are summarized in Table 2 ).

changes were observed in the presence of vesicles composed of POPC:POPG (50:50) and POPC:POPG $(80: 20)$. Nonetheless, significant changes of peptide conformation were achieved in the presence of vesicles composed of mixtures of POPC and POPG, although at higher lipid/peptide molar ratios (Figure 5(C), Table 2), as illustrated by the observation that the peptide conformational changes induced by vesicles composed of POPG at a lipid/peptide ratio of 4 were similar to those induced by POPC:POPG (50:50) vesicles at a lipid/peptide ratio of 8 , and slightly more pronounced than those observed for POPC:POPG $(80: 20)$ vesicles at the highest lipid/peptide molar ratio examined $(\mathrm{L} / \mathrm{P}=32$ ) (Figure 5(C), Table 2).
Overall, analysis of the obtained CD spectra indicates that the changes in peptide conformation induced upon interaction with the different negatively charged vesicles are consistent with an increase in the contribution of an alpha-helical structural component (Table 2).

\section{Peptide Secondary Structure Induced by Negatively Charged Membranes is Dependent on Peptide Sequence}

To elucidate whether the $\mathrm{S} 4_{13}-\mathrm{PV}$ peptide secondary structure is a consequence of specific peptide-membrane interactions, or rather the outcome of nonspecific interactions of electrostatic nature, CD 
experiments were performed using two control peptides generated on the basis of the $\mathrm{S} 4_{13}$-PV peptide sequence, named reverse NLS peptide and scrambled peptide. In the reverse NLS peptide, the sequence corresponding to the SV40 NLS is inverted, whereas the scrambled peptide has a distinct (random) primary sequence (Figure 6(A)).

Similarly to what was previously observed for the $\mathrm{S} 4_{13}$-PV peptide, the reverse NLS and scrambled peptides are completely unstructured in aqueous buffer (Figure 6(B), (C)).

Analysis of the CD spectra of the three peptides in $20 \%$ TFE, an apolar solvent that mimics the hydrophobic environment of a lipid bilayer, demonstrated that the peptides exhibit comparable propensities to be arranged as alpha-helical structures (Figure 6(B)).

Interestingly, the conformational changes of the scrambled peptide induced upon its interaction with the negatively charged membranes composed of POPG were significantly less pronounced than those observed for the $\mathrm{S}_{13}-\mathrm{PV}$ and reverse NLS peptides, and no increase of an alpha-helical structural component was detected for the scrambled peptide (Figure 6(C)).

Since the three peptides have similar physicochemical properties (peptide length, mass and charge) and similar propensities to form alpha-helical structures, the distinct behavior observed for the scrambled peptide in the presence of negatively charged vesicles clearly demonstrates that the conformational changes induced by the membranes are dependent on the peptide sequence. Moreover, these results demonstrate that the $\mathrm{N}$-terminal sequence of the $\mathrm{S} 4_{13}$-PV peptide (which is maintained in the reverse NLS peptide, but absent in the scrambled peptide) is responsible for the formation of the alpha-helical structure.

\section{Amino Acid Sequence Determines the Extent and Mechanism of Peptide Cellular Uptake}

To clarify if the different mode of interaction of the peptides with model membranes, which leads to distinct peptide conformational changes, correlates with a different ability of the peptides to translocate across cell membranes, a comparative analysis of the cellular uptake of the $\mathrm{S}_{13}-\mathrm{PV}$, reverse NLS and scrambled peptides was performed by flow cytometry and confocal microscopy.

Although the $\mathrm{S}_{13}-\mathrm{PV}$ and its derivative peptides have similar physicochemical properties, the extent of cellular uptake of the scrambled peptide, as assessed by flow cytometry, was less efficient than that observed for the $\mathrm{S} 4_{13}-\mathrm{PV}$ and reverse NLS peptides (Figure $7(\mathrm{~A})$ ). Most importantly, confocal fluorescence microscopy analysis revealed distinct subcellular localizations of the peptides: the $\mathrm{S} 4_{13}-\mathrm{PV}$ and reverse NLS peptides were distributed throughout the cytoplasm and nucleus of cells (accumulation in the nucleoli was sometimes

\section{A $\mathrm{S4}_{13}-\mathrm{PV} \quad$ ALWKTLLKKVLKAPKKKRKVC- $\mathrm{NH}_{2}$ reverse NLS ALWKTLLKKVLKAVKRKKKPC- $\mathrm{NH}_{2}$ scrambled KTLKVAKWLKKAKPLRKLVKC- $\mathrm{NH}_{2}$}
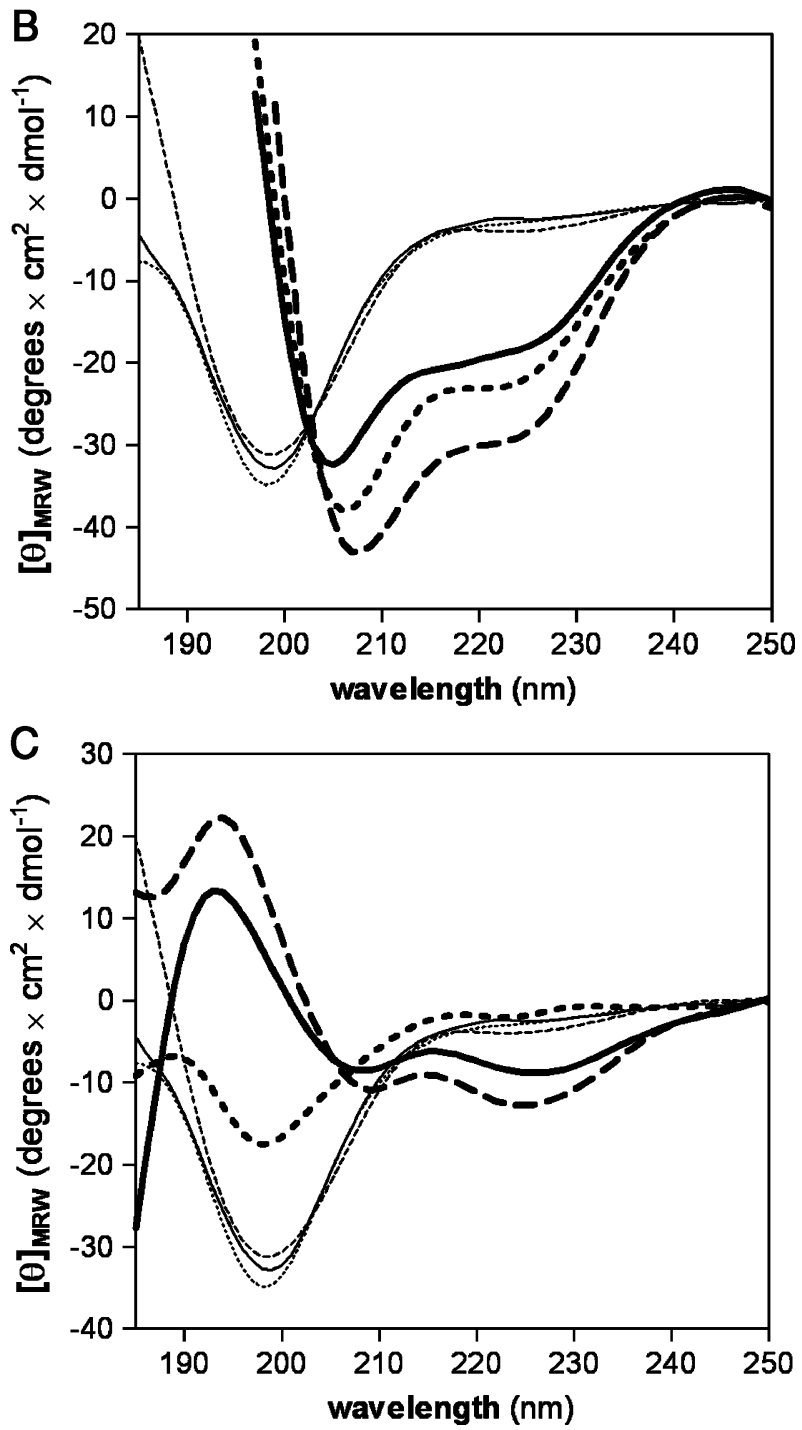

Figure 6 Effect of peptide sequence on the conformational changes induced by negatively charged membranes. (A) Sequences of $\mathrm{S} 4_{13}-\mathrm{PV}$, reverse NLS and scrambled peptides. The reverse NLS and scrambled peptides have an amino acid composition and overall charge identical to the $\mathrm{S} 4_{13}-\mathrm{PV}$ peptide; in the reverse NLS peptide, the sequence corresponding to the SV40 NLS is inverted; the scrambled peptide has a random primary sequence. (B) Effect of solvent polarity on peptide secondary structure. Circular dichroism analysis of the S4 13 -PV (-), reverse NLS (- - - ) and scrambled peptides $(\ldots)$ was performed in aqueous buffer (thin lines; polar) or in 20\% trifluoroethanol (TFE) (thick lines; apolar, 'membrane-mimicking' environment), as described in Materials and Methods. (C) Effect of negatively charged membranes on peptide secondary structure. Circular dichroism analysis of the S4 13 -PV ($(\ldots$.$) was performed in buffer (thin lines) or in the presence$ of negatively charged membranes composed of POPG (thick lines; $\mathrm{L} / \mathrm{P}=4$ ), as described in Materials and Methods. 
evident), whereas the scrambled peptide presented an exclusively punctated cytoplasmic distribution, which is characteristic of an endocytic uptake mechanism (Figure 7(B)).

The results obtained clearly indicate that the peptide-membrane interactions that occur following peptide binding to cells, particularly the peptide conformational changes, determine the mechanism by which the cellular uptake of the peptide occurs, and ultimately its intracellular fate. Moreover, these observations demonstrate that the conformational changes observed for the $\mathrm{S} 4_{13}$-PV peptide are crucial for its ability to efficiently translocate across cell membranes.

\section{DISCUSSION}

Previous studies have demonstrated that the cellular uptake of some CPPs, including the $\mathrm{S} 4_{13}-\mathrm{PV}$ peptide, occurs mainly through a mechanism distinct from endocytosis, strongly suggesting the involvement of a physical process dependent on the direct interaction of such peptides with biological membranes. The main goal of the work described here was the detailed biophysical characterization of the interaction of the S4 $4_{13}-\mathrm{PV}$ peptide with model membranes, aiming at gaining insights into the molecular mechanisms responsible for the ability of this peptide to translocate across biological membranes.

Comparative analysis of the interaction of the $\mathrm{S} 4_{13^{-}}$ PV peptide with the model membranes of different phospholipid compositions demonstrated that the extent of peptide-membrane interactions is dependent on the presence of negatively charged membrane components, providing evidence that the interactions established between the $\mathrm{S} 4_{13}-\mathrm{PV}$ peptide and the membranes are essentially of electrostatic nature. As a consequence of these interactions, clear changes in the intrinsic fluorescence spectra of the $\mathrm{S} 4_{13}-\mathrm{PV}$ peptide could be detected, namely an increase in the fluorescence intensity and a shift of the wavelength of maximal emission toward shorter wavelengths (blue shift), both indicative of changes in the hydrophobicity of the peptide environment. A detailed analysis of these spectral changes highlighted a direct correlation between the partition coefficient of the $\mathrm{S} 4_{13}$-PV peptide into the target membranes and the relative amount of negatively charged membrane components.

A
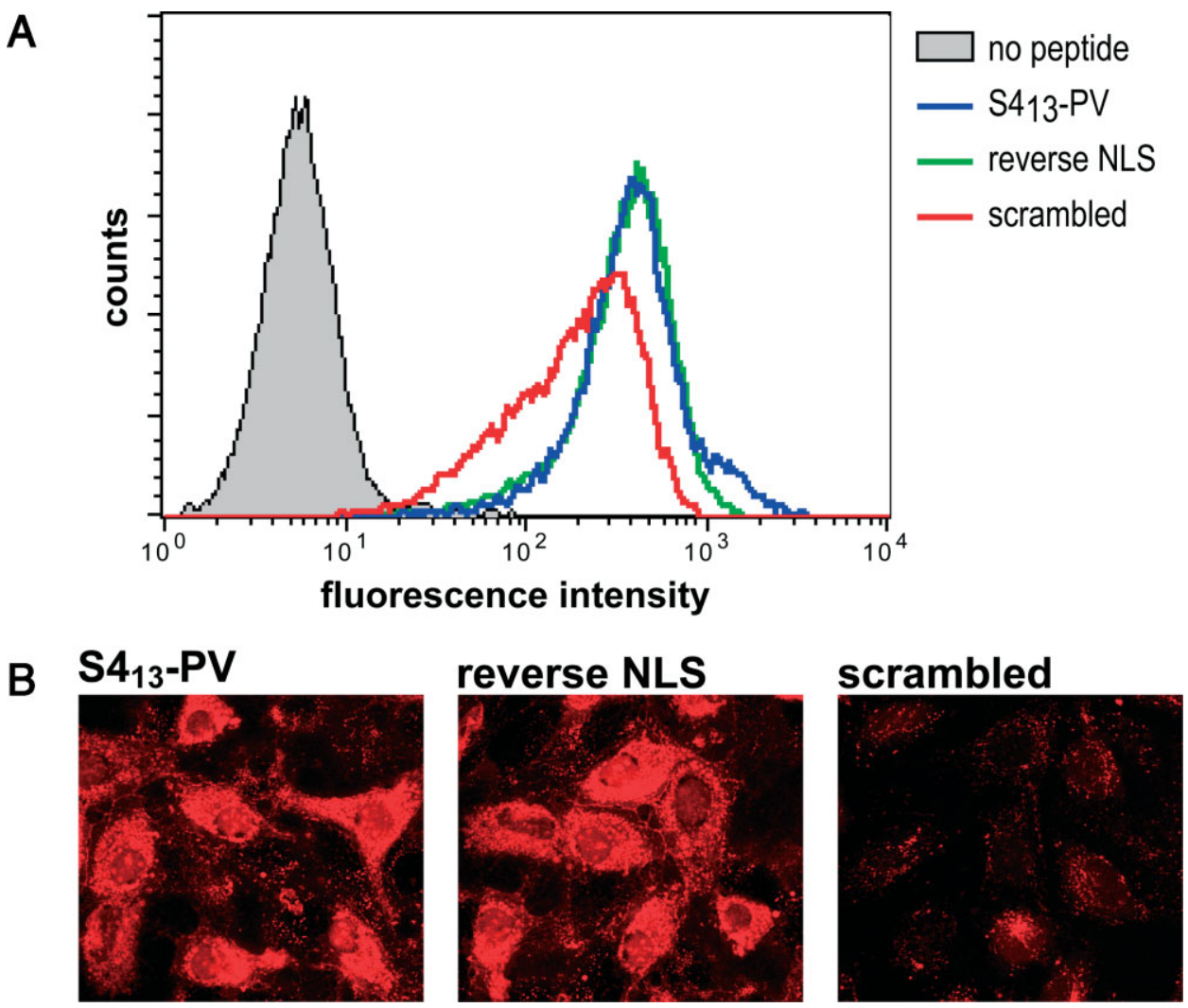

Figure 7 Cellular uptake of $\mathrm{S} 4_{13}-\mathrm{PV}$, reverse NLS and scrambled peptides. (A) Flow cytometry quantification and (B) confocal microscopy analysis of peptide uptake. HeLa cells were incubated for 1 hour, at $37^{\circ} \mathrm{C}$, with $1.0 \mu \mathrm{M}$ of rhodamine-labeled $\mathrm{S} 4_{13}-\mathrm{PV}$, reverse NLS or scrambled peptides. The cells were then either immediately observed by confocal fluorescence microscopy, or analyzed by flow cytometry following cell treatment with trypsin, to remove noninternalized, surface-bound peptide. All experiments were performed in live cells. 
The magnitude of the blue shift described here for the $\mathrm{S} 4_{13}$-PV peptide in the presence of negatively charged vesicles composed of POPG, at a lipid/peptide molar ratio of 40 (from 354 to $324 \mathrm{~nm}$ ), is remarkable when compared to those observed for other CPPs, such as the Penetratin and Transportan peptides (for which shifts of peptide fluorescence to approximately $340 \mathrm{~nm}$ were reported [38-40]), or the Pep-1 peptide (showing a blue shift of $20 \mathrm{~nm}$ [41]). In fact, the wavelength of maximal fluorescence emission of the $\mathrm{S} 4_{13}-\mathrm{PV}$ peptide, observed in the presence of negatively charged vesicles (324 $\mathrm{nm}$ in the case of POPG; uncorrected spectra), is comparable to those classically reported for tryptophan residues that are fully protected from the aqueous environment, such as those found at the extremely hydrophobic environments of the core of several proteins [25].

In agreement with the pronounced spectral changes observed, the $\mathrm{S} 4_{13}-\mathrm{PV}$ peptide, or at least the region of the peptide that contains the tryptophan residue, becomes considerably less exposed to the aqueous milieu as a consequence of its interaction with negatively charged membranes.

Although the extent of partitioning of the $\mathrm{S} 4_{13}-\mathrm{PV}$ peptide into the target membranes was dependent on the composition of the target membrane, it is interesting to note that, at the highest lipid/peptide molar ratio tested $(\mathrm{L} / \mathrm{P}=40)$, the magnitude of the blue shifts observed, as well as the calculated $K_{\mathrm{SV}}$, were comparable. These data demonstrate that, irrespective of the charge density of the target membrane, the interaction of the $\mathrm{S} 4_{13}-\mathrm{PV}$ peptide with the negatively charged membranes leads to a localization of the peptide into an extremely hydrophobic environment, most likely buried into the hydrophobic lipid bilayer. Supporting these results, data from time-resolved fluorescence anisotropy showed a strong reduction of the dynamics of the $\mathrm{S} 4_{13}-\mathrm{PV}$ peptide upon interaction with negatively charged membranes.

Results from CD experiments demonstrated that the interaction of the $\mathrm{S} 4_{13}-\mathrm{PV}$ peptide with the negatively charged vesicles also induces significant changes in the secondary structure of the peptide. Whether these conformational changes are a prerequisite for peptide insertion into the lipid bilayer, or a consequence of this process, remains to be elucidated. Conformational changes induced upon interaction with the negatively charged membranes have also been reported for other peptides that have shown to translocate across biological membranes, such as the Penetratin and Pep-1 peptides [39,41,42].

Although the quantitative analysis of the relative contribution of different structural components to the CD spectra should always be regarded with caution, our results reveal a general trend toward an increase in the alpha-helical structural motif with increasing membrane charge density and lipid/peptide molar ratio. Although the analysis of the $\mathrm{CD}$ spectra indicated the contribution of a beta structural component under some experimental conditions, these results most likely reflect the limited ability of this type of analysis to distinguish beta-type topology from random coil.

In the face of the results showing that the $\mathrm{S}_{13^{-}}$ PV peptide evolves from a random coil in aqueous solution to an alpha helix upon interaction with negatively charged membranes, it would be tempting to rationalize the data obtained from the anisotropy analysis, regarding to the global movement of an alpha helix. Although the formalisms are available (e.g. the dependence of the diffusion coeffient $\mathrm{D}_{\perp}$ on the molecular geometry such as a rigid rod, as described by Tirado and Garcia de la Torre [43]), there are no reliable values regarding the viscosity of the lipid interface where the peptide is located, and two peptide populations, one at the interface and the other in a transmembrane configuration, are likely to be expected. The aim of this approach would be to determine whether the size of the rod would be compatible with the fraction of alpha helix determined by $\mathrm{CD}$, since from lifetime data it is difficult to clearly infer about the secondary structure of the peptide [44].

Although the extent of binding of the $\mathrm{S} 4_{13}-\mathrm{PV}$, reverse NLS and scrambled peptides to cell membranes is similar (data not shown), significant differences were observed in the conformational changes of the three peptides induced upon their interaction with the negatively charged target membranes. Since the $\mathrm{S} 4_{13}-\mathrm{PV}$ and scrambled peptides exhibit similar propensities to be arranged as helical structures, as determined by CD experiments performed in $20 \%$ TFE, the distinct peptide conformational changes induced upon interaction with the negatively charged membranes clearly suggest that the resulting alpha-helical structure of the $\mathrm{S}_{13}{ }^{-}$ $\mathrm{PV}$ peptide is of critical importance for its increased capacity to translocate across biological membranes, as compared to the scrambled peptide. Most importantly, the results demonstrate that the membrane-induced conformational changes determine the mechanism by which cellular uptake of the peptide occurs, as revealed by the distinct subcellular distributions of the three peptides: the scrambled peptide presented an exclusively punctated cytoplasmic pattern, characteristic of an endocytic uptake mechanism, whereas the $\mathrm{S} 4_{13}-\mathrm{PV}$ and reverse NLS peptides exhibited mainly a diffuse subcellular localization, which is consistent with a membrane translocation process.

In contrast to the scrambled peptide, the $\mathrm{S} 4_{13}-\mathrm{PV}$ and reverse NLS peptides have the capacity to be arranged as amphipathic alpha helices, namely considering the 13 amino acids derived from the Dermaseptin peptide. Although this feature is not a requirement for peptide translocation across the membranes, these structural motifs can promote local membrane destabilization, thereby enhancing peptide cellular uptake. 
It was observed that the $\mathrm{S} 4_{13}-\mathrm{PV}$ peptide is able to translocate across biological membranes and accumulate inside cells; however, its inability to interact and partition into neutral model membranes composed of POPC was very intriguing, since the outer leaflets of plasma membranes are essentially composed of neutrally charged phospholipids. Nonetheless, it is worth noting two features of biological membranes that may explain these apparently contradicting observations: the presence of HSPGs at the cell surface and the existence of a membrane potential across the lipid bilayer (negative inside).

Previously, we have demonstrated that the presence of high negatively charged HSPGs at cell surface facilitates the cellular uptake of the $\mathrm{S} 4_{13}-\mathrm{PV}$ peptide $[22,23]$. The results presented here suggest that HSPGs potentiate peptide binding to cell membranes through electrostatic interactions, thereby facilitating the interactions of the peptide with the membranes, which ultimately lead to peptide insertion into the lipid bilayer and translocation. On the other hand, recent studies have demonstrated that the existence of a transbilayer membrane potential is required for the cellular uptake of several CPPs [45-48].

In this context, a two-step mechanism could be invoked for the overall process of peptide translocation across biological membranes: the interface potential (i.e. at the membrane-water interface) is the ruling factor for peptide adsorption at the membrane and is related to the partition coefficient, at least in this study where the partition coefficient is negligible in neutral vesicles; the transbilayer potential (owing to membrane charge asymmetry) is related to the efficiency of internalization. In between these two processes, the peptide undergoes membrane-induced conformational changes, which are essential for the translocation step.

Irrespective of the primary source of the electrostatic attraction between the $\mathrm{S} 4_{13}-\mathrm{PV}$ peptide and biological membranes (negatively charged phospholipids, cell surface proteoglycans, other membrane constituents or a combination of these), the data presented here clearly suggest that the electrostatic interaction established between the $\mathrm{S} 4_{13}$-PV peptide and biological membranes is of crucial importance to peptide cellular uptake. Moreover, our results highlight the relevance of the sequence of the $\mathrm{S} 4_{13}$-PV peptide to the establishment of highly specific peptide-membrane interactions that occur following its binding to cell membranes, as well as the importance of the peptide conformational changes induced by the target membranes to the overall process of translocation of the $\mathrm{S} 4_{13}-\mathrm{PV}$ peptide across biological membranes.

\section{Acknowledgements}

We thank Prof. F. Regateiro, Head of the Centro de Histocompatibilidade de Coimbra (Portugal), for scientific collaboration in this study.
This study was supported by a grant from the Portuguese Foundation for Science and Technology (POCTI/CVT/44854/2002). M. Mano is a recipient of a fellowship from the Portuguese Foundation for Science and Technology.

\section{REFERENCES}

1. Langel U. Handbook of Cell Penetrating Peptides. CRC Press: Boca Raton, FL, 2006.

2. Joliot A, Prochiantz A. Transduction peptides: from technology to physiology. Nat. Cell. Biol. 2004; 6: 189-196.

3. Snyder EL, Dowdy SF. Recent advances in the use of protein transduction domains for the delivery of peptides, proteins and nucleic acids in vivo. Expert Opin. Drug Deliv. 2005; 2: 43-51.

4. Deshayes S, Morris MC, Divita G, Heitz F. Cell-penetrating peptides: tools for intracellular delivery of therapeutics. Cell. Mol. Life Sci. 2005; 62: 1839-1849.

5. Mae M, Langel U. Cell-penetrating peptides as vectors for peptide, protein and oligonucleotide delivery. Curr. Opin. Pharmacol. 2006; 6: 509-514.

6. Lundberg P, Magzoub M, Lindberg M, Hallbrink M, Jarvet J, Eriksson LE, Langel U, Graslund A. Cell membrane translocation of the N-terminal (1-28) part of the prion protein. Biochem. Biophys. Res. Commun. 2002; 299: 85-90.

7. Marinova Z, Vukojevic V, Surcheva S, Yakovleva T, Cebers G, Pasikova N, Usynin I, Hugonin L, Fang W, Hallberg M, Hirschberg D, Bergman T, Langel U, Hauser KF, Pramanik A, Aldrich JV, Graslund A, Terenius L, Bakalkina G. Translocation of dynorphin neuropeptides across the plasma membrane. A putative mechanism of signal transmission. J. Biol. Chem. 2005; 280: 26360-26370.

8. De Coupade C, Fittipaldi A, Chagnas V, Michel M, Carlier S, Tasciotti E, Darmon A, Ravel D, Kearsey J, Giacca M, Cailler F. Novel human derived cell penetrating peptides for specific subcellular delivery of therapeutic biomolecules. Biochem. J. 2005; 390: $407-418$.

9. Vives E, Brodin P, Lebleu B. A truncated HIV-1 Tat protein basic domain rapidly translocates through the plasma membrane and accumulates in the cell nucleus. J. Biol. Chem. 1997; 272: 16010-16017.

10. Derossi D, Joliot AH, Chassaing G, Prochiantz A. The third helix of the Antennapedia homeodomain translocates through biological membranes. J. Biol. Chem. 1994; 269: 10444-10450.

11. Morris MC, Depollier J, Mery J, Heitz F, Divita G. A peptide carrier for the delivery of biologically active proteins into mammalian cells. Nat. Biotechnol. 2001; 19: 1173-1176.

12. Lundberg M, Wikstrom S, Johansson M. Cell surface adherence and endocytosis of protein transduction domains. Mol. Ther. 2003; 8: $143-150$.

13. Richard JP, Melikov K, Vives E, Ramos C, Verbeure B, Gait MJ, Chernomordik LV, Lebleu B. Cell-penetrating peptides. A reevaluation of the mechanism of cellular uptake. J. Biol. Chem. 2003; 278: 585-590.

14. Vives E, Richard JP, Rispal C, Lebleu B. TAT peptide internalization: seeking the mechanism of entry. Curr. Protein. Pept. Sci. 2003; 4: $125-132$.

15. Richard JP, Melikov K, Brooks H, Prevot P, Lebleu B, Chernomordik LV. Cellular uptake of unconjugated TAT peptide involves clathrin-dependent endocytosis and heparan sulfate receptors. J. Biol. Chem. 2005; 280: 15300-15306.

16. Ferrari A, Pellegrini V, Arcangeli C, Fittipaldi A, Giacca M, Beltram F. Caveolae-mediated internalization of extracellular HIV1 tat fusion proteins visualized in real time. Mol. Ther. 2003; 8: 284-294.

17. Fittipaldi A, Ferrari A, Zoppe M, Arcangeli C, Pellegrini V, Beltram F, Giacca M. Cell membrane lipid rafts mediate caveolar 
endocytosis of HIV-1 Tat fusion proteins. J. Biol. Chem. 2003; 278: 34141-34149.

18. Kaplan IM, Wadia JS, Dowdy SF. Cationic TAT peptide transduction domain enters cells by macropinocytosis. J. Control. Release 2005; 102: 247-253.

19. Wadia JS, Stan RV, Dowdy SF. Transducible TAT-HA fusogenic peptide enhances escape of TAT-fusion proteins after lipid raft macropinocytosis. Nat. Med. 2004; 10: 310-315.

20. Foerg C, Ziegler U, Fernandez-Carneado J, Giralt E, Rennert R, Beck-Sickinger AG, Merkle HP. Decoding the entry of two novel cellpenetrating peptides in HeLa cells: lipid raft-mediated endocytosis and endosomal escape. Biochemistry 2005; 44: 72-81.

21. Hariton G, Feder R, Mor A, Graessmann A, Brack W, Jans D, Gilon C, Loyter A. Targeting of nonkaryophilic cell-permeable peptides into the nuclei of intact cells by covalently attached nuclear localization signals. Biochemistry 2002; 41: 9208-9214.

22. Mano M, Teodosio C, Paiva A, Simoes S, Pedroso de Lima MC. On the mechanisms of the internalization of S4(13)-PV cell penetrating peptide. Biochem. J. 2005; 390: 603-612.

23. Mano M, Henriques A, Paiva A, Prieto M, Gavilanes F, Simoes S, Pedroso de Lima MC. Cellular uptake of S4(13)-PV peptide occurs upon conformational changes induced by peptide-membrane interactions. Biochim. Biophys. Acta 2006; 1758: 336-346.

24. Bartlett GR. Phosphorus assay in column chromatography. J. Biol. Chem. 1959; 234: 466-468.

25. Lakowicz JR. Principles of Fluorescence Spectroscopy, (2nd edn). Kluwer Academic/Plenum Publishers: New York, 1999.

26. De Kroon AI, Soekarjo MW, De Gier J, De Kruijff B. The role of charge and hydrophobicity in peptide-lipid interaction: a comparative study based on tryptophan fluorescence measurements combined with the use of aqueous and hydrophobic quenchers. Biochemistry 1990; 29: 8229-8240.

27. Coutinho A, Prieto M. Ribonuclease $T_{1}$ and alcohol dehydrogenase fluorescence quenching by acrylamide. A laboratory experiment for undergraduate students. J. Chem. Educ. 1993; 70: 425-428.

28. Loura LM, Fedorov A, Prieto M. Resonance energy transfer in a model system of membranes: application to gel and liquid crystalline phases. Biophys. J. 1996; 71 : 1823-1836.

29. Marquardt DW. An algorithm for least-squares estimation of nonlinear parameters. J. Soc. Ind. Appl. Math. (SIAM J.) 1963; 11: $431-441$.

30. Santos NC, Prieto M, Castanho MA. Quantifying molecular partition into model systems of biomembranes: an emphasis on optical spectroscopic methods. Biochim. Biophys. Acta 2003; 1612: 123-135.

31. Marsh D. CRC Handbook of Lipid Bilayers. CRC Press: Boca Raton, FL, 1990.

32. Willis KJ, Szabo AG. Conformation of parathyroid hormone: timeresolved fluorescence studies. Biochemistry 1992; 31: 8924-8931.

33. Valeur B, Weber G. Resolution of the fluorescence excitation spectrum of indole into the $1 \mathrm{La}$ and $1 \mathrm{Lb}$ excitation bands. Photochem. Photobiol. 1977; 25: 441-444.
34. Vogel H, Nilsson L, Rigler R, Voges KP, Jung G. Structural fluctuations of a helical polypeptide traversing a lipid bilayer. Proc. Natl. Acad. Sci. U.S.A. 1988; 85: 5067-5071.

35. Contreras LM, de Almeida RF, Villalain J, Fedorov A, Prieto M. Interaction of alpha-melanocyte stimulating hormone with binary phospholipid membranes: structural changes and relevance of phase behavior. Biophys. J. 2001; 80: 2273-2283.

36. Lipari G, Szabo A. Effect of librational motion on fluorescence depolarization and nuclear magnetic resonance relaxation in macromolecules and membranes. Biophys. J. 1980; 30: 489-506.

37. Kinosita K Jr, Kawato S, Ikegami A. A theory of fluorescence polarization decay in membranes. Biophys. J. 1977; 20: 289-305.

38. Magzoub M, Kilk K, Eriksson LE, Langel U, Graslund A. Interaction and structure induction of cell-penetrating peptides in the presence of phospholipid vesicles. Biochim. Biophys. Acta 2001; 1512: 77-89.

39. Magzoub M, Eriksson LE, Graslund A. Comparison of the interaction, positioning, structure induction and membrane perturbation of cell-penetrating peptides and non-translocating variants with phospholipid vesicles. Biophys. Chem. 2003; 103: 271-288.

40. Thoren PE, Persson D, Esbjorner EK, Goksor M, Lincoln P, Norden B. Membrane binding and translocation of cell-penetrating peptides. Biochemistry 2004; 43: 3471-3489.

41. Deshayes S, Heitz A, Morris MC, Charnet P, Divita G, Heitz F. Insight into the mechanism of internalization of the cellpenetrating carrier peptide Pep- 1 through conformational analysis. Biochemistry 2004; 43: 1449-1457.

42. Magzoub M, Eriksson LE, Graslund A. Conformational states of the cell-penetrating peptide penetratin when interacting with phospholipid vesicles: effects of surface charge and peptide concentration. Biochim. Biophys. Acta 2002; 1563: 53-63.

43. Tirado MM, Garcia de la Torre J. Translational friction coefficients of rigid, symmetric top macromolecules. Application to circular cylinders. J. Chem. Phys. 1979; 71 : 2581-2587.

44. Dahms TE, Szabo AG. Probing local secondary structure by fluorescence: time-resolved and circular dichroism studies of highly purified neurotoxins. Biophys. J. 1995; 69: 569-576.

45. Terrone D, Sang SL, Roudaia L, Silvius JR. Penetratin and related cell-penetrating cationic peptides can translocate across lipid bilayers in the presence of a transbilayer potential. Biochemistry 2003; 42: 13787-13799.

46. Henriques ST, Castanho MA. Consequences of nonlytic membrane perturbation to the translocation of the cell penetrating peptide pep-1 in lipidic vesicles. Biochemistry 2004; 43: 9716-9724.

47. Rothbard JB, Jessop TC, Wender PA. Adaptive translocation: the role of hydrogen bonding and membrane potential in the uptake of guanidinium-rich transporters into cells. Adv. Drug Deliv. Rev. 2005; 57: 495-504.

48. Bjorklund J, Biverstahl H, Graslund A, Maler L, Brzezinski P. Realtime transmembrane translocation of penetratin driven by lightgenerated proton pumping. Biophys. J. 2006; 91: L29-L31. 